\title{
Intra- and International Risk-Sharing in the Short Run and the Long Run*
}

\author{
Sascha O. Becker ${ }^{\dagger}$ \\ University of Munich and CESifo \\ Mathias Hoffmann ${ }^{\ddagger}$ \\ University of Dortmund
}

September 1, 2004

\begin{abstract}
We investigate empirically how industrialized countries and U.S. states share consumption risk at horizons between one and thirty years. U.S. federal states share about 50 percent of their permanent idiosyncratic risk through cross-state capital income flows. While insurance against transitory fluctuations in output is virtually complete, OECD countries do not share any of their permanent idiosyncratic risk. Our results suggest that purely transaction cost based theories cannot explain the home bias, since the potential welfare gains from insurance against permanent shocks would by far outweigh that of insuring against transitory variation. We conclude that permanent and transitory shocks constitute two qualitatively different kinds of risk and that various forms of endogenous market incompleteness may render permanent shocks a lot harder to insure, in particular at the international level.

Keywords: Consumption Risk Sharing, Home Bias, International Business Cycles, Panel Vector Autoregressions

JEL Classification: F36, F41
\end{abstract}

${ }^{*}$ The authors are grateful to seminar participants at Boston College, the University of British Columbia, the Dublin Economics Workshop and the CESifo Macro Area Conference as well as the ESRC workshop 'The Evolving Macroeconomy' at Warwick University. In particular, we would like to thank Mike Artis, Nils Gottfries, Philip Lane, Jim Nason, Bent Sørensen and Oved Yosha for their comments and encouragement. Hoffmann acknowledges financial support from the UK Economic and Social Research Council under grant \# L138251037.

${ }^{\dagger}$ Center for Economic Studies, University of Munich, Schackstrasse 4, 80539 Munich, Germany; Tel. +49 (89) 2180-6252; sbecker@lmu.de

${ }^{\ddagger}$ Corresponding Author. Department of Economics, University of Dortmund, 44221 Dortmund, Germany; Tel. +49 (231) 755-3102; M.Hoffmann@wiso.uni-dortmund.de 


\section{Introduction}

International non-diversification is one of the big puzzles of international finance. Starting with French and Poterba (1991), the literature documents that countries' equity portfolios are heavily biased towards domestic assets. This portfolio home bias puzzle finds its natural correspondence in the lack of international consumption risk sharing ${ }^{1}$ countries share a lot less of their idiosyncratic consumption risk than do regions within a country.

To understand the sources of this lack of international consumption risk sharing, it is important to identify in which way countries and regions achieve the degree of consumption risk sharing that we see in the data. Asdrubali, Sørensen and Yosha (1996), henceforth ASY, have suggested a simple decomposition of output risk that allows to distinguish between two important channels through which risk can be shared:

First, countries or regions can pool their risks by exchanging claims to their output, say in the form of equity or through fiscal transfer arrangements. Since the claims to output are exchanged before uncertainty is resolved, we call this the ex ante channel of risk sharing. The cross holdings of claims to each others' output then induce income flows that allow countries to stabilize their income in the face of output shocks. ASY therefore also refer to the $e x$ ante channel as income smoothing.

Second, a country or region can further smooth its consumption through the sale or purchase of foreign assets or through borrowing and lending. Since this entails that current income is already observed and uncertainty about outputs is already resolved, we call this the ex post channel of risk sharing.28

ASY and Sørensen and Yosha (1998), henceforth SY, find that the main source of the lack of international consumption risk sharing is that countries do almost not obtain any insurance, i.e. ex ante risk sharing, whereas U.S.

\footnotetext{
${ }^{1}$ This lack of consumption risk sharing is documented in a slightly separate literature: Backus, Kehoe and Kydland (1992) demonstrated that international consumption correlations are too low to be explained by models with perfect capital mobility and complete asset markets.

${ }^{2}$ The two channels can be distinguished along one other important dimension: risk averse agents will want to avoid variability ex ante, even in an atemporal economy. Ex ante sharing of risk therefore only entails income flows in the cross-section of of countries. A further smoothing of consumption ex post, however, only makes sense in a multi-period world. We therefore also use the words cross-sectional and inter-temporal channel for the ex ante and the ex post channels respectively.

${ }^{3}$ We reserve the term 'insurance' to mean income smoothing through ex ante diversification. In keeping with most papers in the literature, however, we use the term risk sharing to denote all forms of consumption smoothing or insurance (income smoothing), that the residents of a country or region may employ to minimize unwanted idiosyncratic variance in consumption.
} 
federal states share 50 percent (inclusive of fiscal transfers) of their consumption risk in this way. Conversely, both U.S. federal states as well as OECD countries achieve surprisingly similar levels of ex post risk sharing H $^{4}$

What the literature so far has not answered is to what extent these findings depend on the forecasting horizon. The relative role of the channels as well as the total amount of risk sharing achieved is likely to vary as we change the forecasting horizon. Identifying the time profile of the contribution of channels to the total amount of risk sharing may give us further important indications as to the frictions that are important in international financial markets.

In this paper, we therefore extend the method of ASY (1996) to a fully dynamic framework. $5^{5}$ We use data from industrialised countries as well as from U.S. federal states to evaluate the contribution of ex ante and ex post risk sharing to overall consumption risk sharing at different horizons. Our method - based on a cointegrated panel vector autoregression (VAR) - also allows us to identify permanent and transitory shocks and to ask whether they get smoothed through different channels.

The distinction between permanent and transitory shocks is of paramount importance for understanding the sources of the home bias. First, most economic theories would associate the permanent and transitory parts of output with different types of economic shocks: typically, permanent shocks are associated with the supply side, whereas the transitory or business cycle part is associated with demand side shocks. Secondly, and more importantly, permanent and transitory shocks may constitute very different kinds of risk in terms of their insurability in financial markets: consumption cannot be smoothed ex post in the face of permanent shocks but can only be insured ex ante. Insurance against permanent shocks therefore requires a more elaborate asset market structure in which state-contingent assets such as e.g. equity are traded, whereas consumption smoothing in the face of transitory shocks can be achieved with simple assets such as loans and bonds (see Baxter and Crucini (1995)).

Before we proceed to present our econometric model and the data, we provide a preview of our results:

1. U.S. federal states share roughly one half of their idiosyncratic risk ex ante, whereas there is almost no ex ante insurance at the international

\footnotetext{
${ }^{4}$ Mélitz and Zumer (1999) extended the ASY study by including further exogenous variables like regional size and the real interest rate. Their results by and large corroborate those of ASY.

${ }^{5}$ Athanasoulis and van Wincoop (2000) provide an analysis of risk-sharing at various time horizons but their model does not allow the identification of risk-sharing channels.
} 
level. In both data sets, the contribution of the ex ante channel is virtually independent of the forecasting horizon. Conversely, the amount of ex post risk sharing achieved is about the same in both data sets but declines from about 30 to 50 percent in the short run to between 10 and 15 percent at horizons of 15 years and beyond, implying that the relative lack of international consumption risk sharing worsens in the long run.

2. The second important result of our paper is that the apparent lack of international consumption risk sharing is in fact a failure to insure against permanent fluctuations whereas the risk associated with transitory shocks gets almost completely shared. At first sight, this seems to constitute a puzzle: for a given marginal cost of transacting in international financial markets, economic agents would rather insure against permanent shocks. In particular, our finding seems inconsistent with theories in which fixed transaction costs are put forward as a possible explanation of the home bias 6

Rather, we suggest the following interpretation of our results: permanent and transitory shocks constitute two qualitatively different kinds of risk and various forms of endogenous market incompleteness may make it harder to share the risk associated with permanent shocks, in particular at the international level. If the state of the world cannot be ascertained at all or if it is very costly to do so, problems of moral hazard may limit the enforceability of certain contracts. This problem is more pertinent for state-contingent assets rather than non-state contingent ones, such as bonds. Because permanent variation in relative output and income levels can be insured only through state-contingent assets, it may be harder for regions and countries alike to insure against permanent shocks.7

3. The empirical literature on consumption risk-sharing is based on re-

\footnotetext{
${ }^{6}$ While our results could be qualitatively consistent with fixed transaction costs that differ across asset classes (such as equity and bonds), the welfare gains from insuring against permanent risk seem to dwarf those to be had by insuring against risks at the business cycle frequency (compare e.g. the calculations in van Wincoop (1999) to those in Lucas (1987)). Transaction costs would therefore have to vary enormously across asset classes in order to provide some leverage in explaining our results quantitatively. Since turnover in international equity positions is quite high (Tesar and Werner (1995)), we do not believe that this is the case.

${ }^{7}$ At a theoretical level, this mechanism has first been suggested by Kocherlakota (1996). Kehoe and Perri (2002) explore the mechanism quantitatively in a calibrated general equilibrium framework and find that it can account for the low consumption correlations observed in international data.
} 
gressions of variables such as country-specific consumption and income on endowment variables, notably output. The maintained assumption in all of these studies is that fluctuations in output are exogenous. If, however, consumption and output are incidentally correlated for reasons other than market incompleteness, then this could in principle lead to wrong inference with respect to the amount of international consumption risk sharing. As an additional result this paper provides evidence based on principal components analysis that shows that shocks to output are the predominant source of variability in standard data sets 8

We structure our analysis as follows:

Section two outlines our econometric approach. Our main way of estimating risk-sharing patterns at various horizons is by means of a cointegrated panel vector autoregression. By exploiting equilibrium relations between the data, we can identify permanent and transitory shocks to output with only minimal identifying assumptions. Section three describes the data and our empirical strategy. We report the results of our analysis in section four and offer more discussion and a summary of conclusions in section five.

\section{A dynamic model of risk sharing}

In this section we propose a dynamic econometric model that enables us to analyse how income risk is shared over time. Our decomposition is based on the work by ASY. Crucini (1999) has offered a formal justification for this decomposition and we briefly summarize it here:

In a world in which cross-border ownership of assets is possible, a country's or region's income is a weighted average of per capita home and world outputs:

$$
I N C_{t}^{j}=\lambda Y_{t}^{*}+(1-\lambda) Y_{t}^{j}
$$

where $Y^{j}$ and $Y^{*}$ denote home and foreign (world or U.S. average) per capita output respectively and $I N C^{j}$ is country or region $j$ 's income. The coefficient $\lambda$ measures the degree of diversification of country or region $j$. Through

\footnotetext{
${ }^{8}$ This finding is also consistent with the results of other researchers: Backus, Kehoe and Kydland (1992) discuss a model in which country-specific productivity shocks generate asymmetric fluctuations in labor input because labor is not mobile between countries. If utility is non-separable in consumption and leisure, this may lead to a positive correlation in relative output and relative consumption although financial markets are complete. But the results in Backus, Kehoe and Kydland also show that such a mechanism cannot quantitatively rationalize the consumption correlation puzzle. Our, empirical, results point in the same direction.
} 
diversification, the region will generally achieve some income smoothing. We will refer to this notion of income smoothing as ex ante risk sharing because it requires that the international portfolio weight $\lambda$ has to be set before $Y^{j}$ and $Y^{*}$ are observed.

Optimal consumption in country $j$ will generally be smoother than income because consumption should react only to the permanent level of income. Therefore, further smoothing will generally take place and we refer to this as consumption smoothing or risk sharing ex post.

The covariance of the relative $9^{9}$ income-output ratio with relative output can therefore be thought of as a measure of ex ante risk sharing. In the same mould, the covariance of the relative income-consumption ratio with relative output measures ex post risk sharing. This is the decomposition suggested in ASY (1996). This paper develops a fully dynamic version of the ASY decomposition ${ }^{10}$ Our objective is to characterize the joint uncertainty of relative output, income and consumption at different forecasting horizons. To this end, we decompose the $k$ period ahead mean squared prediction error of per capita output conditional on information available at time $t$ :

$$
\operatorname{var}\left(y_{t+k} \mid \mathcal{I}_{t}\right)=\operatorname{var}\left(y_{t+k}-\boldsymbol{E}_{t}\left(y_{t+k}\right)\right)
$$

where $\boldsymbol{E}(\cdot)$ is the expectations operator and $\mathcal{I}_{t}$ is the information set that is available as of time $t$. We now write this conditional variance as

$$
\begin{aligned}
\operatorname{var}\left(y_{t+k} \mid \mathcal{I}_{t}\right)= & \operatorname{cov}\left(y_{t+k}-i n c_{t+k}, y_{t+k} \mid \mathcal{I}_{t}\right) \\
& +\operatorname{cov}\left(i n c_{t+k}-c_{t+k}, y_{t+k} \mid \mathcal{I}_{t}\right) \\
& +\operatorname{cov}\left(c_{t+k}, y_{t+k} \mid \mathcal{I}_{t}\right)
\end{aligned}
$$

We can divide (2) by $\operatorname{var}\left(y_{t+k} \mid \mathcal{I}_{t}\right)$ to get:

$$
1=\beta_{K}(k)+\beta_{C}(k)+\beta_{U}(k)
$$

\footnotetext{
${ }^{9}$ We use the term 'relative' as equivalent to 'idiosyncratic' and mean the logarithmic or percentage deviation from the world (or country) aggregate. To save on notation, we denote relative variables with lower-case letters and, where possible, we drop the country or region index ' $j$ '. Hence, relative output is $y=\ln \frac{Y}{Y^{*}}$, relative income is inc $=\ln \frac{I N C}{I N C^{*}}$, and relative consumption is $c=\ln \frac{C}{C^{*}}$

${ }^{10}$ Our analysis here focuses on the distinction between ex ante and ex post insurance and we do not distinguish a fiscal insurance channel. Given that most fiscal transfer schemes are based on rules that were written ex ante, we would tend to include this channel into the ex ante channel. A closer analysis of this issue is, however, beyond the scope of this paper. For a survey of the literature on fiscal risk sharing see von Hagen (2000) who also provides a number of theoretical explanations for the generally limited extent of fiscal risk sharing found in the data. At the international level, SY (1998) find that fiscal transfers play a limited role for insurance among EU countries. For the larger group of OECD countries, they report that fiscal transfers play no role for risk sharing at all.
} 
where

$$
\boldsymbol{\beta}(k)=\left[\begin{array}{c}
\beta_{K}(k) \\
\beta_{C}(k) \\
\beta_{U}(k)
\end{array}\right]=\frac{1}{\operatorname{var}\left(y_{t+k} \mid \mathcal{I}_{t}\right)}\left[\begin{array}{c}
\operatorname{cov}\left(y_{t+k}-i n c_{t+k}, y_{t+k}\right) \\
\operatorname{cov}\left(i n c_{t+k}-c_{t+k}, y_{t+k}\right) \mid \mathcal{I}_{t} \\
\operatorname{cov}\left(c_{t+k}, y_{t+k}\right)
\end{array}\right]
$$

Throughout the paper, we refer to the vector sequence $\boldsymbol{\beta}(k)_{k=1,2 \ldots}$ as dynamic risk sharing profile. For given $k$, the elements of the vector $\boldsymbol{\beta}(k)$ can be interpreted as the coefficients in regressions of the form

$$
\begin{aligned}
\left(y_{t+k}-i n c_{t+k}\right)-\boldsymbol{E}_{t}\left[y_{t+k}-i n c_{t+k}\right] & =\beta_{K}(k)\left(y_{t+k}-\boldsymbol{E}_{t}\left[y_{t+k}\right]\right)+u_{t+k} \\
\left(i n c_{t+k}-c_{t+k}\right)-\boldsymbol{E}_{t}\left[i n c_{t+k}-c_{t+k}\right] & =\beta_{C}(k)\left(y_{t+k}-\boldsymbol{E}_{t}\left[y_{t+k}\right]\right)+v_{t+k} \\
c_{t+k}-\boldsymbol{E}_{t}\left[c_{t+k}\right] & =\beta_{U}(k)\left(y_{t+k}-\boldsymbol{E}_{t}\left[y_{t+k}\right]\right)+w_{t+k}
\end{aligned}
$$

and this setting also allows us to associate them with the various channels of risk sharing. We call the set of equations (4) the 'risk sharing regressions'. Clearly, in the empirical implementation, only two of the three equations will have to be estimated, since the coefficients of $\boldsymbol{\beta}(k)$ will always add to unity.

The $y-i n c$ differential reflects international factor income flows. Hence, $\beta_{K}(k)$ measures to what extent capital income from abroad shields GNP (income) from variation in GDP (output). Therefore, $\beta_{K}(k)$ can be thought of as representing the ex ante, cross-sectional or income-smoothing dimension of consumption insurance that is achieved (primarily) through cross-border or cross-regional ownership of assets ${ }^{11}$

The inc $-c$ differential measures savings and $\beta_{C}(k)$ gives the contribution of the ex post, intertemporal or consumption smoothing channel of insurance at horizon $k$. Finally, $\beta_{U}(k)$ is the residual covariance between consumption growth and output growth, reflecting the undiversified or unsmoothed component of consumption.

\subsection{Estimating risk sharing profiles}

There are in principle two ways of implementing equations (4) empirically. The first is what we call the regression-based approach. The expectation terms are replaced by observable variables and then $\boldsymbol{\beta}(k)$ is estimated from a regression. The most straightforward way of substituting for the expectation

\footnotetext{
${ }^{11}$ At the international level, SY (1998) demonstrate that labour income flows between industrialised countries are negligible. The same holds true for interest payments on international bonds and loans. We can therefore think of the GDP-GNP differential as a good proxy for contingent capital income such as equity returns.
} 
terms is by the value as of time $t$ of the respective variable. This amounts to differencing the data at horizon $k$. ASY and SY use this simple method to provide preliminary evidence on risk sharing at various horizons. To set the scene, we will also present some regression-based evidence in this paper. Specifically, we will report the results from differenced regressions at horizon $k=1$. Since this just amounts to the original ASY specification, we call this set of regressions the 'ASY regressions'. We associate the vector of coefficients from the ASY regressions with risk sharing in the short run or at business cycle frequencies and call it $\boldsymbol{\beta}^{S R}=\left[\begin{array}{ll}\beta_{K}^{S R} & \beta_{C}^{S R}\end{array}\right]^{\prime}$.

To obtain a regression-based characterization of long-run risk sharing, we run the risk sharing regressions in levels rather than differences, i.e. in (4) we drop the expectation terms and then estimate the respective regression. This amounts to an estimate of the unconditional covariation between the levels of relative output, income and consumption and can therefore be thought as a proxy of $\boldsymbol{\beta}(k)$ as $k$ tends to infinity. ${ }^{12}$ We label the corresponding vector of risk sharing coefficients $\boldsymbol{\beta}^{L R}=\left[\begin{array}{ll}\beta_{K}^{L R} & \beta_{C}^{L R}\end{array}\right]^{\prime}$.

The second way to implement (4) is to go for a full charaterization of all moments of output, income and consumption by means of a vector autoregression (VAR). This VAR-based approach is the solution we advocate in this paper. It offers a number of advantages over the regression-based approach.

First and most importantly, a VAR allows us to identify permanent and transitory shocks and to obtain separate dynamic risk sharing profiles for each of these types of shocks.13 Clearly, this would not be possible within a regression-based approach. As we have argued earlier, the separate risk sharing profiles for permanent and transitory shocks are meant to give us important indications as to the potential sources of the home bias. Our identification of permanent and transitory shocks comes naturally in a VAR context since economic theory imposes a cointegrating restriction on the data: in the long-run the average country's consumption must equal its income.

A second advantage of the VAR is that it provides a complete description of the moments of the data at all leads and lags. Hence, the dynamic risk sharing profile is a closed-form function of the VAR parameters. If we were to obtain an estimate of the risk sharing profile from a sequence of regression equations differenced at horizon $k=1,2 \ldots$, the analytic link between the

\footnotetext{
${ }^{12}$ Such level regressions could be spurious as pure time series regressions since they involve unit root processes that are not cointegrated. In a panel, however, the level risk sharing regressions are well-defined as long-run relations in the sense of Phillips and Moon (1999). In section 3 we discuss how we estimate the level regressions.

${ }^{13}$ We refer to the dynamic risk sharing profile associated with the permanent shocks as $\boldsymbol{\beta}^{P}(k)$ and to the one associated with transitory shocks as $\boldsymbol{\beta}^{T}(k)$.
} 
different $\boldsymbol{\beta}(k)$ for $k=1,2 \ldots$ would remain blurred. Note also that, since differencing amounts to substituting $\boldsymbol{E}_{t}\left(x_{t+k}\right) \approx x_{t}$ (where $x$ stands for any of the variables in (4)), we would implicitly assume that the data are well approximated by random walks. This approximation can be problematic: if $x_{t}$ has a transitory component, its changes will be predictable, at least over shorter horizons.

Third, for our purposes, the VAR also offers advantages over differenced or 'long horizon' regressions in terms of estimation: the differenced regression can either be estimated with overlapping or with non-overlapping observations. If non-overlapping observations are used, there are fewer and fewer observations as $k$ increases in relation to the sample size. This may lead to estimation inefficiency and considerable small sample distortions, which is particularly disturbing in the context of our analysis since one of our main objectives is to gauge the relative role of the channels in the long-run. Alternatively, with overlapping observations, the residuals will be serially correlated and the estimation procedure will then have to correct for this in a more or less ad hoc manner ${ }^{14}$ In our view it is preferable to model the patterns of temporal (and cross equation) dependence head on by using a VAR. ${ }^{15}$ Since the VAR treats all variables symmetrically as endogenous, we also minimize the risk of simultaneity bias in $\boldsymbol{\beta}(k)$ that may arise if relative output, income and consumption are correlated for reasons other than market incompleteness. ${ }^{16}$

The remainder of this section discusses the implementation of (4) using a (panel) VAR and the identification of permanent and transitory shocks. It contains some technical material which can be skipped by those readers who only have a general or cursory interest in our results.

\footnotetext{
${ }^{14}$ Even after correcting for serial correlation in the errors, the small sample distortions of long-horizon regressions can be quite considerable, as recent research in this area has shown (see e.g. Valkanov (2003) and Coe and Nason (2004)). While it is often argued that long-horizon regressions may carry important power gains over, say, a VAR approach, a recent study by Valkanov (2003) casts doubt on this conclusion.

${ }^{15}$ Hodrick (1992) also advocates the VAR as a robust method to estimate parameters such as $\boldsymbol{\beta}(k)$.

${ }^{16}$ Clearly, this can only be true for $k>1$. In annual data there are many plausible reasons why consumption and income could still be coincidentally correlated with output. A crucial presumption of the ASY approach is that output is the exogenous source of shocks, whereas income and consumption are not systematically subject to independent variation. There is no direct way to test this assumption. Still, if the ASY presumption is correct, then shocks to the system should predominantly originate in output, whereas income and consumption should not by themselves be an important source of shocks. We further explore this issue below.
} 


\subsection{Dynamic risk sharing profiles in a VAR}

In this and the following subsections we now discuss the technical issues involved in estimating dynamic risk sharing profiles and in the identification of permanent and transitory shocks.

We first discuss, how the risk sharing profile $\boldsymbol{\beta}(k)$ can be completely characterized from a VAR. We then consider how a simple country or regional budget constraint (in the long run, income and consumption have to be equal) imposes a cointegrating restriction that can then be exploited to identify permanent and transitory shocks which will also allow us to obtain $\boldsymbol{\beta}^{P}(k)$ and $\boldsymbol{\beta}^{T}(k)$.

To obtain estimates of $\boldsymbol{\beta}(k)$, we have to consider the conditional moments of the vector

$$
\boldsymbol{X}_{t}=\left[\begin{array}{c}
y_{t} \\
y_{t}-i n c_{t} \\
i n c_{t}-c_{t}
\end{array}\right]
$$

We assume that only the past of $\boldsymbol{X}_{t}$ enters the information set, so that $I_{t}=\left\{\boldsymbol{X}_{\tau}\right\}_{\tau=1}^{t}$ and that expectations coincide with linear projections. These assumptions allow us to form $\boldsymbol{E}\left(\boldsymbol{X}_{t} \mid I_{t-1}\right)$ by projecting $\boldsymbol{X}_{t}$ on its own past. Hence, $\boldsymbol{X}_{t}$ has a vector autoregressive (VAR) representation of the form

$$
\boldsymbol{\Phi}(\boldsymbol{L}) \boldsymbol{X}_{t}=\boldsymbol{\epsilon}_{t}
$$

where $\boldsymbol{\Phi}(\boldsymbol{L})$ is a $3 \times 3$ matrix polynomial in the lag operator, $\boldsymbol{L}$, which satisfies the condition that the roots of $\operatorname{det}(\boldsymbol{\Phi}(\boldsymbol{z}))$ lie on or outside the unit circle. Note that we explicitly allow $\boldsymbol{X}_{t}$ to have unit roots and to be potentially cointegrated, which will be important in our empirical implementation. The unexpected component of $\boldsymbol{X}_{t}$ is given by $\boldsymbol{\epsilon}_{t}=\boldsymbol{X}_{t}-\boldsymbol{E}_{t-1}\left(\boldsymbol{X}_{t}\right)$ and reflects the one-period ahead forecast error.

Now let $\boldsymbol{\Omega}$ denote the variance-covariance matrix of $\boldsymbol{\epsilon}_{t}$ and let $\omega_{i j}$ be the entry in the $i$-th row and $j$-th column of $\boldsymbol{\Omega}$. Then, given the ordering of the variables in $\boldsymbol{X}_{t}$, the elements of $\boldsymbol{\Omega}$ are just

$$
\begin{aligned}
\omega_{11} & =\operatorname{var}\left(y_{t} \mid \mathcal{I}_{t-1}\right) \\
\omega_{21} & =\operatorname{cov}\left(y_{t}-i n c_{t}, y_{t} \mid \mathcal{I}_{t-1}\right) \\
\omega_{31} & =\operatorname{cov}\left(i n c_{t}-c_{t}, y_{t} \mid \mathcal{I}_{t-1}\right)
\end{aligned}
$$

so that the relative contribution of the channels one period ahead is 


$$
\beta_{K}(1)=\frac{\omega_{21}}{\omega_{11}} \text { and } \beta_{C}(1)=\frac{\omega_{31}}{\omega_{11}}
$$

and $\beta_{U}(1)$ is given by

$$
\beta_{U}(1)=1-\beta_{K}(1)-\beta_{C}(1)
$$

In order to generalize our approach to arbitrary forecast horizons, we need a description of the data dynamics. This description is given by the VAR in (5) so that for $k>1$, the coefficients of $\boldsymbol{\beta}(k)$ will not only be functions of $\boldsymbol{\Omega}$ but also of the VAR coefficients.

We note that the reduced form residual matrix $\Omega$ represents the meansquared prediction error of the VAR one period ahead. We therefore also write $\boldsymbol{\Omega}(1)$ instead of $\boldsymbol{\Omega}$. More generally, we denote with $\boldsymbol{\Omega}(k)$ the $k$-period ahead mean squared prediction error of $\boldsymbol{X}_{t}$. Whereas $\boldsymbol{\Omega}(1)$ is a parameter of the VAR, for $k>1, \Omega(k)$ is a function of $\boldsymbol{\Omega}(1)$ and the VAR coefficients. Very much as $\boldsymbol{\beta}(1)$ is given by ratios of the entries of $\boldsymbol{\Omega}(1)$, so $\boldsymbol{\beta}(k)$ will then be defined by the elements of $\Omega(k)$.

To obtain a general analytic expression for $\Omega(k)$ we recognize that by the assumptions on the VAR in (5), $\boldsymbol{X}_{t}$ is difference stationary. Hence, there is a Wold representation of $\boldsymbol{\Delta} \boldsymbol{X}_{t}$

$$
\Delta \boldsymbol{X}_{t}=\boldsymbol{C}(\boldsymbol{L}) \boldsymbol{\epsilon}_{t}
$$

where $\boldsymbol{C}(\boldsymbol{L})$ is an infinite-order MA matrix polynomial. Then we can express the prediction error of $\Delta \boldsymbol{X}_{t+k}$

$$
\boldsymbol{\Delta} \boldsymbol{X}_{t+k}-\boldsymbol{E}_{t}\left(\boldsymbol{\Delta} \boldsymbol{X}_{t+k}\right)=\sum_{l=1}^{k} \boldsymbol{C}_{l} \boldsymbol{\epsilon}_{t+l}
$$

This allows us to write the mean squared prediction error $\Omega(k)$ of the level variable $\boldsymbol{X}_{t}$ as

$$
\boldsymbol{\Omega}(k)=\operatorname{var}\left(\boldsymbol{X}_{t+k}-\boldsymbol{E}_{t}\left(\boldsymbol{X}_{t+k}\right)\right)=\operatorname{var}\left\{\sum_{l=1}^{k}\left[\boldsymbol{\Delta} \boldsymbol{X}_{t+l}-\boldsymbol{E}_{t}\left(\boldsymbol{\Delta} \boldsymbol{X}_{t+l}\right)\right]\right\}
$$

which from (8) can be written as

$$
\boldsymbol{\Omega}(k)=\sum_{l=1}^{k}(k-l)^{2} \boldsymbol{C}_{l} \boldsymbol{\Omega}(1) \boldsymbol{C}_{l}^{\prime}
$$


Now let the entries of $\Omega(k)$ be denoted by $\omega_{i j}(k)$. Then, in analogy to (6) above, the coefficients of $\boldsymbol{\beta}(k)$ are just:

$$
\beta_{K}(k)=\frac{\omega_{21}(k)}{\omega_{11}(k)} \text { and } \beta_{C}(k)=\frac{\omega_{31}(k)}{\omega_{11}(k)}
$$

and again

$$
\beta_{U}(k)=1-\beta_{K}(k)-\beta_{C}(k) .
$$

\subsection{Cointegration, permanent and transitory shocks}

Relative output, income and consumption are likely to be integrated processes. In the (levels) VAR specification (5) we have allowed for this possibility as well as for the possibility of cointegration between the variables. Indeed, our model imposes a cointegrating restriction on the data: ex ante risk sharing may decouple a country's or region's output from its income, but in the long run, ex post income and consumption will have to be equal. By the permanent income hypothesis, consumption should correspond to the permanent component of income, so that

$$
C_{t}^{j}=I N C_{t}^{j P}=\lambda Y_{t}^{* P}+(1-\lambda) Y_{t}^{j P}
$$

where the superscript ' $\mathrm{P}$ ' denotes the permanent component.

Because world income and output coincide and because the consumption function (11) also holds for the world as a whole, we get

$$
\frac{C_{t}^{j}}{C_{t}^{*}}=\frac{I N C_{t}^{j P}}{I N C_{t}^{* P}}
$$

Taking logarithms on both sides, we find that relative (log) consumption and $(\log )$ income should be cointegrated with cointegrating vector $\left[\begin{array}{cc}1 & -1\end{array}\right]^{\prime}$. In an open economy with risk-sharing, consumption should follow the permanent level of income, after all transfers that arise through (cross-sectional, i.e. ex ante) risk sharing (see Crucini (1999)). We note that this cointegrating relationship between $c$ and inc is independent of how much ex ante risk sharing is achieved through international portfolio diversification. ${ }^{17}$

Johansen (1995) has shown that the presence of a stationary variable in a vector of otherwise integrated series implies a cointegration restriction with

\footnotetext{
${ }^{17}$ Strictly speaking, a country could increase its foreign asset position through capital gains so that (relative) income and consumption can diverge forever. We do not think that this extreme is case is relevant - certainly not for the 'representative' country or state that is modelled by our panel approach.
} 
a unit cointegrating vector. Therefore, $\boldsymbol{X}_{t}$ is cointegrated with cointegrating vector $\boldsymbol{\delta}^{\prime}=\left[\begin{array}{lll}0 & 0 & -1\end{array}\right]$. Indeed, panel unit root tests based on Im, Pesaran and Shin (2003) suggested that $i n c-c$ is stationary in both data sets. According to Granger's representation theorem, our level VAR model in (5) therefore has an error correction representation of the form

$$
\Gamma(\boldsymbol{L}) \Delta \boldsymbol{X}_{t}=\gamma \boldsymbol{\delta}^{\prime} \boldsymbol{X}_{i t-1}+\boldsymbol{\epsilon}_{t}
$$

where $\boldsymbol{\delta}$ is the (unit) cointegrating vector from above and $\boldsymbol{\gamma}=\left[\begin{array}{lll}\gamma_{1} & \gamma_{2} & \gamma_{3}\end{array}\right]^{\prime}$ represents the vector of adjustment coefficients. The short-run dynamic adjustment coefficients $\boldsymbol{\Gamma}(\boldsymbol{L})$ is implicitly defined by the expansion of the VAR lag-polynomial $\boldsymbol{\Phi}(\mathbf{L})=\boldsymbol{\Phi}(\mathbf{1})+\boldsymbol{\Gamma}(\mathbf{L})(\mathbf{1}-\mathbf{L})$.

The presence of cointegration in our model allows the identification of permanent and transitory shocks without any further identifying assumptions: our system is trivariate with one cointegrating relationship. Hence, there are two permanent shocks that represent the innovations to the two common trends (Stock and Watson (1988)) and one transitory disturbance. Expanding $\mathbf{C}(\mathbf{L})=\mathbf{C}(\mathbf{1})+\mathbf{C}^{*}(\mathbf{L})(\mathbf{1}-\mathbf{L})$, and cumulating the moving average representation of $\boldsymbol{\Delta} \boldsymbol{X}_{t}$, we obtain the Beveridge-Nelson (1981) decomposition

$$
\boldsymbol{X}_{t}=\mathbf{C}(\mathbf{1}) \sum_{l=0}^{t} \boldsymbol{\epsilon}_{l}+\boldsymbol{C}^{*}(\boldsymbol{L}) \boldsymbol{\epsilon}_{t}
$$

Johansen (1995), showed that the long-run response matrix $\mathbf{C}(\mathbf{1})$ of a cointegrated system has the form

$$
\mathbf{C}(\mathbf{1})=\boldsymbol{\delta}_{\perp}\left(\boldsymbol{\gamma}_{\perp}^{\prime} \mathbf{\Phi}(\mathbf{1})^{-1} \boldsymbol{\delta}_{\perp}\right)^{-1} \gamma_{\perp}^{\prime}
$$

where the subscript ' $\perp$ ' denotes the orthogonal complement of the respective matrix. Hence, changes in the unit-root component of $\boldsymbol{X}_{t}$ can be written as

$$
\mathrm{C}(\mathbf{1}) \boldsymbol{\epsilon}_{t}=\boldsymbol{A} \boldsymbol{\gamma}_{\perp}^{\prime} \boldsymbol{\epsilon}_{t}
$$

where, in our case with two common trends, $\boldsymbol{A}=\boldsymbol{\delta}_{\perp}\left(\boldsymbol{\gamma}_{\perp}^{\prime} \boldsymbol{\Phi}(\mathbf{1})^{-1} \boldsymbol{\delta}_{\perp}\right)^{-1}$ is $3 \times 2$ and the $(2 \times 1)$-vector $\boldsymbol{\gamma}_{\perp}^{\prime} \boldsymbol{\epsilon}_{t}$ represents the innovations to the unit-root component of the whole system. These are our permanent shocks that we denote with $\boldsymbol{\pi}_{t}$ :

$$
\pi_{t}=\gamma_{\perp}^{\prime} \epsilon_{t}
$$


Finally, the presence of one cointegrating relationship also implies that there is a purely transitory shock $\tau_{t}$ that does not have a long-run impact on any of the components of $\boldsymbol{X}_{t}$. Following Johansen (1995), this shock is identified by requiring that it is orthogonal to $\gamma_{\perp}^{\prime} \boldsymbol{\epsilon}_{t}$. Therefore, we must have:

$$
\tau_{t}=\gamma^{\prime} \Omega^{-1} \epsilon_{t}
$$

We note that this identification is purely based on one single restriction that is implied by our theoretical framework: consumption is determined by the permanent level of ex post income. This is why relative consumption and relative income will be cointegrated. Therefore, the variables in our trivariate VAR specification must be subject to two permanent shocks and one transitory shock.

This cointegrated setup now allows us to identify the variance contributions of permanent and transitory shocks to output that we need as the basis for the computation of the separate risk sharing profiles for permanent and transitory shocks. One important feature of a cointegrated system is that the relative variance contribution of permanent and transitory shocks are independent of how the permanent and transitory shocks are identified among themselves: our model has two permanent shocks that are given by the twodimensional vector $\boldsymbol{\pi}_{t}$. Any mapping $\boldsymbol{S}_{\pi} \boldsymbol{\pi}$ with a non-singular $\boldsymbol{S}_{\pi}$ will also identify a set of permanent shocks. If we were to conduct impulse response analysis, we would therefore need to orthogonalize the elements of $\boldsymbol{\pi}_{t}$ using a priori restrictions on $\boldsymbol{S}_{\pi}$. This would require that we impose just-identifying restrictions. However, there is no need to do so if all we are interested in is in identifying the contribution of $\boldsymbol{\pi}_{t}$ to the variance of $\boldsymbol{X}_{t}$ (and there notably: output).

In the technical appendix, we show that $\boldsymbol{\Omega}(k)=\Omega^{P}(k)+\Omega^{T}(k)$ where

$$
\begin{aligned}
& \boldsymbol{\Omega}^{P}(k)=\sum_{l=1}^{k}(k-l)^{2} C_{l}\left[\boldsymbol{\Omega} \gamma_{\perp}\left(\boldsymbol{\gamma}_{\perp}^{\prime} \boldsymbol{\Omega} \gamma_{\perp}\right)^{-1} \boldsymbol{\gamma}_{\perp}^{\prime} \boldsymbol{\Omega}\right] \boldsymbol{C}_{l}^{\prime} \\
& \boldsymbol{\Omega}^{T}(k)=\sum_{l=1}^{k}(k-l)^{2} \boldsymbol{C}_{l}\left[\boldsymbol{\gamma}\left(\boldsymbol{\gamma}^{\prime} \boldsymbol{\Omega}^{-1} \boldsymbol{\gamma}\right)^{-1} \boldsymbol{\gamma}^{\prime}\right] \boldsymbol{C}_{l}^{\prime}
\end{aligned}
$$

Both $\boldsymbol{\Omega}^{P}(k)$ and $\boldsymbol{\Omega}^{T}(k)$ are independent of $\boldsymbol{S}_{\pi}$ and $\boldsymbol{S}_{\tau}$, i.e. of any particular rotation of permanent or transitory shocks. This is a very desirable property of our procedure. One major shortcoming of structural VAR analysis is that it requires the researcher to impose non-testable just-identifying 
restrictions. In our setting, economic theory provides one cointegrating relationship that fully identifies the relative importance of permanent and transitory shocks for the variation in output.

Once we have obtained estimates of $\boldsymbol{\Omega}^{P}(k)$ and $\boldsymbol{\Omega}^{T}(k)$ it is then straightforward to obtain the corresponding risk sharing profiles $\boldsymbol{\beta}^{P}(k)$ and $\boldsymbol{\beta}^{T}(k)$ in analogy to (10) above.

\section{Data and Empirical Implementation}

Our international data are those also used by used by Sørensen and Yosha (1998). The source are the OECD National Accounts Main Aggregates volume 1, OECD Economic Outlook, period 1960-1996. As output measure we use gross domestic product (GDP), income is measured by gross national product (GNP) and consumption by household final consumption expenditure $(\mathrm{C})$. The data are deflated using the respective country's consumer price index and transformed into per capita data by using population data from the same source.

The U.S. regional data are those used in ASY and were downloaded from Oved Yosha's webpage. They consist of gross-state product and personal income data from the Bureau of Economic Analysis (BEA) and range from 1963-1990. Personal consumption data at the state level is not available. ASY have therefore used retail sales data. Unfortunately, retail sales are only a part of total personal consumption, so in order to obtain an estimate of total personal consumption, ASY re-scaled the retail sales data by the ratio of aggregate U.S. private consumption to aggregate U.S. retail sales. Finally, state and local government consumption is added to obtain state consumption. More details on both the international as well as the U.S. data sets are contained in the appendix.

Both the regression-based as well as the VAR approaches are empirically implemented as panels. To account for the potential role of global (or U.S. wide) shocks (time-specific effects) that may create uninsurable output variability, we formulated the data for each country (or state) relative to the global (or U.S. wide) aggregate. In the setup of the panel, we multiplied the data of each country by its population weight. ASY (1996) have emphasized that measurement error may be present in U.S. state level data and that output is particularly likely to be measured with error in small states. To alleviate this problem, ASY suggest to weight the data with the state-specific variance. We follow this practice here.

As a first step, we estimate the original ASY regressions, i.e. we regress $\Delta y-\Delta i n c$ and $\Delta i n c-\Delta c$ on $\Delta y$ by (panel) OLS. We control for country- 
specific fixed effects by removing country-specific means from all variables. To obtain a regression-based measure of risk sharing in the long-run, we also estimate the same regressions in levels, i.e. $y-i n c$ and inc $-c$ on $y$. As discussed earlier, this regression could be spurious in time series, but it describes a panel long-run relation in the sense of Phillips and Moon (1999). To account for the possible endogeneity of the regressors, we employ the panel dynamic OLS procedure (PDOLS) suggested by Mark and Sul (2004), including one lead and lag respectively of $\Delta y$. Again, we remove countryspecific means.

Then, we proceeded to the main exercise, the panel estimation of the vector autoregression (5). We follow the procedure proposed by Holtz-Eakin, Newey and Rosen (1988) that we explain in much detail in the technical appendix. We obtained both unconditional estimates as well as estimates based on the permanent-transitory decomposition described above 18

We are not aware of a generally accepted procedure for selecting the lag length in a panel VAR. We first explored standard information criteria. These would generally indicate a short lag length of one or two periods, which we think is very plausible, given that our data is of annual frequency. As we will see in the following section, using one or two lags throughout also leads to values of $\boldsymbol{\beta}(k)$ for large $k$ that are close to the estimates of $\boldsymbol{\beta}^{L R}$ obtained from the levels regressions. Since both $\boldsymbol{\beta}^{L R}$ and $\boldsymbol{\beta}(k)_{k \rightarrow \infty}$ approximate the long-run covariance structure of $\boldsymbol{X}_{t}$, this provides an additional check of plausibility on the choice of lag length.

\section{Results}

In the selection of countries we used for our investigation, we deliberately only included OECD economies. This ensures that countries are sufficiently homogenous to warrant treatment in a single panel estimation. Our panel of countries also includes several interesting sub-groupings and we will report results for these throughout. These sub-groups include a core of OECD countries (the G7 economies plus Australia, Austria, Belgium, Denmark, Finland and Sweden). This grouping is also studied in Sørensen and Yosha (1998) and serves as a reference group. We also study the G7 as a separate subgrouping, as well as the European Union of 15 countries before the 2004 enlargement (EU15). Another group of countries we explore are the starting members of the EMU as of January 1999 to which we refer as EMU11. In

\footnotetext{
${ }^{18}$ As a robustness check of the homogeneity assumption underlying the panel VAR, we used a 'mean group estimator' as suggested in Pesaran and Smith (1995), with very similar results.
} 
all exercises that we are going to present in this section, we compare the outcome from the analysis of international data to the results from the U.S. state-level data set.

\subsection{Regression-based evidence}

To set the scene, we run the ASY decomposition on both data sets and all subgroups of countries. We also present the results from the level (long run) risk sharing regressions. Table 1 provides an overview of this first set results. For the short run (column 1), our findings are very similar to those reported in both ASY (1996) and SY (1998): while in international data generally more than 60 percent of idiosyncratic output variation remain uninsured, this is the case for only about 15 percent in U.S. state level data. ${ }^{19}$ While the total contribution of the intertemporal channel is between 30 and 40 percent in both data sets, there is a lot more ex ante risk sharing in U.S. data ${ }^{20}$ Table 1, column 2 shows long run estimates obtained with the PDOLS procedure explained above. A very interesting pattern emerges: the role of the ex post channel declines very markedly in all country groupings as well as for the United States. But for the U.S., the ex ante channel continues to contribute substantially to risk sharing. We find that roughly two thirds of all long run output risk among U.S. federal states is shared ex ante. For groups of countries, the role of the ex ante channel remains very tiny. But generally, both the ex ante and ex post channels are found to be insignificant in international data, suggesting that idiosyncratic output risk is not shared internationally in the long-run. Almost all risk sharing between countries takes place as consumption smoothing ex post and it is limited to shorter horizons.

\footnotetext{
${ }^{19}$ There is a current debate about how measurement error in regional data might affect the conclusions from risk sharing regressions. While Del Negro (2002) suggests that accounting for measurement error in output could overturn the general finding of high levels of risk sharing among US federal states, Sørensen and Yosha (2002) cast doubt on this conclusion: they argue that Del Negro uses two conceptually different measures of state level output to identify measurement error. Both measures are based on the same nominal data, but in one case these data are deflated with the CPI, in the other with state level output deflators. Sørensen and Yosha (2002) then show that the difference between these output concepts mainly reflects fluctuations in the value of state output in terms of the state's consumption bundle. Fluctuations in the relative value of its output constitute a substantial part of the state's idiosyncratic risk and should therefore not be associated with measurement error. As we described in section 3, in this paper we account for measurement error by weighting the U.S. data with a measure of the state-specific output variance.

${ }^{20}$ Qualitatively, our results are the same as in ASY and SY. Slight differences in point estimates are due to the fact that we do plain OLS estimation while ASY do GLS.
} 


\subsection{Risk sharing profiles from the VAR}

To analyze this evidence in more detail and to understand how the relative role of the channels changes over time, we now turn to the risk sharing profiles that we estimated from the cointegrated panel VAR. Table 2 provides the relative contributions of the intertemporal and the cross-sectional channels at forecast horizons of one, three, five, ten, fifteen and thirty years. The general impression from table 1 is confirmed: first of all, countries share a lot less risk ex ante than do U.S. federal states. This holds true at all horizons. Generally the contribution of the ex ante channel does not change very much over time. But the role of the ex post channel declines very markedly. Still, at the maximum forecast horizon of 30 years that we report here, the role of the ex post channel is generally significant in international data, in contrast to the findings in table 1 . The VECM model uses additional information on the cointegrating properties of the data that is not possible to incorporate into the levels risk sharing regression: a country's consumption will have to equal its income in the long-run. This restriction limits the uncertainty surrounding the prediction of future consumption levels relative to output and forces the long- run contribution of the ex post channel to be zero. 21 Against the backdrop of these remarks, the results obtained from table 1 and table 2 are remarkably consistent. Countries insure a lot less than do states within the U.S. and this is true at all uncertainty horizons. For both the U.S. and the international data sets we find that ex post risk sharing becomes less important over time. Clearly, this reflects the fact that in the long run, a country's consumption must equal its income so that a smoothing of permanent shocks ex post is not possible. However, whereas U.S. federal states continue to share a sizeable portion of their long-run idiosyncratic risk ex ante, countries achieve very little ex ante insurance at all horizons. Putting these observations together, it appears that the lack of international risk sharing is even more severe at longer horizons.

One possible reason why ex ante risk sharing holds up so well in the long run in U.S. data could be that fiscal redistribution substitutes for insurance

\footnotetext{
${ }^{21}$ The long-run covariance matrix of $\boldsymbol{X}_{t}, \boldsymbol{\Omega}_{\infty}=\lim _{k \rightarrow \infty} \boldsymbol{\Omega}(k) / k=\boldsymbol{C}(1) \boldsymbol{\Omega}(1)^{\prime}$ is of reduced rank. In particular, the third row and column of $\boldsymbol{\Omega}_{\infty}$ contain only zeros. Small biases in the estimation of the VAR parameters may induce very slow convergence of $\sum \boldsymbol{C}_{l}$ to $\boldsymbol{C}(1)$. Hence $\boldsymbol{\Omega}(k)$ will not be numerically close to singularity, even for very large $k$. This could lead to the spurious conclusion that the ex post channel contributes to risk sharing at all horizons. To avoid this problem, we express $\boldsymbol{C}_{l}$ in terms of the parameters of the Beveridge-Nelson decomposition, so that $\sum_{0}^{k} \boldsymbol{C}_{l}=\boldsymbol{C}(1)+\boldsymbol{C}_{k}^{*}$ in 9 . We then use the closed-form representation $\boldsymbol{C}(1)=\boldsymbol{\delta}_{\perp}\left(\boldsymbol{\gamma}_{\perp}^{\prime} \mathbf{\Phi}(\mathbf{1})^{-1} \boldsymbol{\delta}_{\perp}\right)^{-1} \boldsymbol{\gamma}_{\perp}^{\prime}$ and truncate the expansion of $\boldsymbol{C}_{k}^{*}$ after 100 terms. This ensures that $\boldsymbol{\Omega}(k) / k$ converges to a singular limit within 100 periods.
} 
through capital markets over time. In this case it would not be surprising that the lack of international risk sharing becomes more severe in the long run, since fiscal transfer mechanisms are virtually absent at the international level. We therefore also estimated the risk sharing profiles for the U.S. by separately considering a fiscal channel as measured by the wedge between personal income and personal disposable income at the state level. Our results show only a very limited role for the fiscal channel - around 5 percent at all horizons ${ }^{22}$ A more detailed analysis of how various forms of fiscal transfers provide risk sharing at various horizons and, in particular, to what extent these transfers are redistributive is a potentially important area for future research. For our purposes here, however, we only note that U.S. federal states share more long-run risk than do countries mainly because they insure better through private capital markets. The fiscal channel does not seem to contribute much to our understanding of the lack of international risk sharing and we will continue to abstract from it in the remainder of our analysis.

The profile of risk sharing at various time horizons allows us to draw a more precise picture of how countries or regions achieve risk sharing while maintaining the simplicity and elegance of the ASY decomposition. In particular, we can now study how permanent and transitory shocks get insured. Before we do so in the next sub-section, we relate our first results to the earlier literature and discuss one important presumption of the ASY-approach.

A novelty of our paper is that we use a fully-fledged dynamic econometric specification to study the time-profile of risk sharing. The results from the dynamic specification so far are qualitatively consistent with those we obtained from the regression-based specifications and that were reported in table 1. At intermediate horizons, they are also in line with earlier results by other researchers. Using the 'differencing cum regression' method, SY (1998) find that the unsmoothed component at the three-years horizon is somewhat larger (roughly 75 percent) than at the 1-year horizon (roughly 60 percent). In a similar way, Canova and Ravn (1996) report that lower frequency fluctuations in income seem less insured than higher frequency fluctuations in international data. Our results are in line with these findings: the contribution of the intertemporal channel is a lot lower in the long-run but the message from the dynamic profiles is also that it decreases very slowly. At business cycle frequencies, and actually far beyond, the ex post channel generally continues to play an important role, indicating that shocks of remarkable degrees of persistence can be smoothed ex post.

\footnotetext{
${ }^{22}$ Regression-based evidence reveals that fiscal transfers help to smooth 12 percent of the idiosyncratic risk in the short run, very close to the 13 percent found by ASY. In the long run (levels) regression the coefficient is slightly negative and insignificant.
} 
The VAR-based approach presented in this paper allows us to examine an important assumption that underlies the ASY-approach: if the outputincome differential and the income-consumption differential actually serve as buffers for shocks to output, they should be driven by exactly the same shocks that drive output. In other words: the notion underlying ASY and the related literature is that shocks originate in output fluctuations and get smoothed at various levels. But the various aggregates, i.e. the Y-INC differential and the INC-C differential that act as buffers, should not themselves be the source of shocks.

We explore this assumption by conducting a principal components analysis of the shocks to our econometric model. If the presumption underlying the ASY approach is correct, then there should be a single dominant principal component in the reduced form errors that we get from the estimation of the VAR. Furthermore, this principal component should be highly correlated with innovations in the $\Delta y$-equation of our model but virtually uncorrelated with innovations in the other two equations.

In table 3 , we give the share of the total variation in $[\Delta y, \Delta y-\Delta i n c, \Delta i n c-$ $\Delta c$ ] that is explained by the first principal component of $\Omega$. As it turns out, we do find a dominant principal component in the reduced-form errors for all groupings of countries and U.S. states that we examine. We then also calculated the correlation of this principal component with unexpected innovations in the $\Delta y$-equation, i.e. $\varepsilon_{1 t i}$ as well as the $\Delta y-\Delta i n c$ - and $\Delta i n c-\Delta c$ equations, $\varepsilon_{i 2 t}$ and $\varepsilon_{i 3 t}$ respectively. These correlations are given in columns 2-4 of table 3. Our results suggest that, indeed, shocks to $\Delta y$ drive the joint dynamics of $[\Delta y, \Delta y-\Delta i n c, \Delta i n c-\Delta c]$. This is an independent finding of this paper that is nonetheless very important as it underscores the overall validity of our method and the static version of it that has been proposed in ASY (1996) and SY (1998), and that has also been applied in Mélitz and Zumer (1999).

\subsection{Permanent and transitory shocks}

As we have argued earlier, there is a conceptual difference between permanent and transitory variation in relative output levels: insurance against permanent shocks requires the use of state-contingent assets. Conversely, transitory shocks can be completely smoothed through credit markets. Table 4 presents one of the central results of this paper: the dynamic risk sharing profiles by source of uncertainty, i.e. for permanent $\left(\left\{\boldsymbol{\beta}^{P}(k)\right\}_{k=1,2 \ldots}\right)$ and transitory shocks $\left(\left\{\boldsymbol{\beta}^{T}(k)\right\}_{k=1,2 \ldots}\right)$. These are calculated based on 10 and (15). The table also gives the share of transitory shocks in the variation of relative output levels. As becomes apparent, transitory shocks account 
for 10-40 percent of output fluctuations at business cycle frequencies, i.e. at horizons between one and five years and depending on the country or regional grouping.

The most important feature of the results in table 4 is that insurance against transitory variation in relative output appears quite complete, although the standard errors are at times relatively large for $\beta_{C}^{T}$. Conversely, both OECD countries and U.S. federal states are incompletely insured against permanent shocks. But while U.S. federal states still share about half of their permanent idiosyncratic risk, OECD countries share virtually none of it. This implies that the apparent lack of international risk sharing gets worse in the long run. We discuss the economic implications of this finding in more detail in the next section.

At the international level the ex post channel plays a relatively small but always significant role for sharing permanent risks. While this role declines over time, it can be quite important in the short run.

We suggest two interpretations of this finding: the first is that permanent shocks trigger gradual responses in relative outputs. If output does not reach its new permanent level instantaneously but only after an adjustment period, this provides scope for optimal consumption smoothing behaviour. The coefficient $\beta_{C}^{P}$ can even become negative if the output response to a positive permanent shock is monotonically increasing, and if that permanent shock has a permanent impact on relative income (since it is not diversified ex ante). Then, current consumption should adjust instantaneously to the new permanent level whereas income, following the path of relative outputs, will only adjust gradually. Hence, it is optimal to temporarily reduce savings (i.e. the difference between income and consumption) in the face of positive permanent shocks. This may explain the de-smoothing effect that we find for the EU15 and the EMU11 and that is reflected in the negative coefficients we find for the ex post channel. The same logic can also rationalize a positive coefficient of smoothing if permanent shocks trigger a non-monotonic impulse response of output: if income temporarily overshoots its new long-run level then it is optimal for the country to adjust consumption incompletely, leading to a change in savings that comoves positively with changes in output.

A second possible explanation why the ex post channel can play a role in insuring countries against permanent shocks is that the difference between income and consumption not only reflects borrowing and lending but more generally, the purchase and sale of financial assets. Also, consumption can deviate from permanent income if discounted income streams are not the only component of wealth. A country or region could be very well diversified ex ante but its income may still move very closely with its output because the country does not reap capital income flows but rather realises capital gains 
from foreign portfolio holdings. Lane and Milesi-Ferretti (2003) find that capital gains and other wealth effects play an important role in international risk sharing. In our metric, this would imply that very little ex ante risk sharing is detected ${ }^{23}$

While U.S. federal states insure a lot better against permanent shocks than do countries, our findings for transitory variation in relative output levels are surprisingly similar across data sets. In most country groups and also among U.S. states, we find that the risks associated with transitory shocks are shared virtually completely. Most of this is achieved ex post and the relative role of the channels does not fluctuate over time. Sometimes, the results for the intertemporal channel would even suggest that there is oversmoothing of consumption in response to transitory shocks, i.e. in particular the coefficients of $\beta_{C}^{T}(k)$ are found to be higher than unity. While this feature is not generally very significant, it is particularly pronounced in the United States data. We note that our consumption data for the U.S. is based on retail sales. A number of authors, including ASY and Del Negro (2002), acknowledge that these data are very noisy, and this noise is likely to show up in our transitory component and we would therefore not overemphasize this result.

Our finding that almost all transitory fluctuations get smoothed in international data seems to contrast with the observation made by Feldstein and Horioka (1980) that savings and investment comove closely in most industrialised economies. To see that there is no contradiction, let us define the savings rate as $s=(I N C-C) / I N C$. Approximating $s \approx \ln (I N C)-\ln (C)$, we can write $i n c-c=s-s^{*}=i-i^{*}+n x-n x^{*}$ where $i$ and $i^{*}$ are the home and world average investment rates and $n x$ is net exports over income. World average net exports are zero and therefore $s^{*}=i^{*}$. Provided the common (world) component is big enough, savings and investment rates can well move closely together, even though idiosyncratic fluctuations in savings rates help to smooth idiosyncratic consumption to a large extent. Hence, our findings can easily be reconciled with the Feldstein-Horioka observation. But, clearly, our results in this paper have nothing to say to what extent idiosyncratic movements in savings rates are explained by either relative fluctuations in investment rates or by trade balance fluctuations. Mélitz and Zumer (1999) explore this issue more closely. In the context of the intertemporal approach to the current account, Hoffmann (2003) finds that current account fluctu-

\footnotetext{
${ }^{23}$ In this respect, the association of cross-sectional and inter-temporal risk sharing with the ex post and ex ante channel would seem imperfect. But note that, while trade in equity and the realization of capital gains are the result of an ex ante optimization about the allocation of risk, the transaction only take place after the resolution of uncertainty, i.e. ex post.
} 
ations are a good proxy of country-specific variation in output, supporting the view that consumption smoothing may have an important international component.

\section{Discussion and Conclusion}

Our findings from the dynamic specification are in line with the results from the static regressions in table 1 and the findings in ASY (1996) and SY (1998) who document that insurance among U.S. states is more complete mainly because there is more ex ante insurance. Indeed, they suggest that the stylized fact that consumption insurance between countries is less complete than within them is largely a failure of world financial markets to provide insurance against permanent output shocks ${ }^{24}$ U.S. federal states achieve better insurance against permanent shocks because they share more risk ex ante. Since insurance, i.e. ex ante risk sharing, is the only way in which a country can shield its consumption from permanent asymmetric variation, this implies that the lack of international consumption risk sharing (as gauged against evidence from regional data) is even worse in the long run.

Our results shed important light on the nature of the frictions that are responsible for the lack of international consumption risk sharing: by and large we find that all transitory shocks are shared while insurance against permanent variation is very incomplete. At the same time, the potential welfare gains from better insurance against permanent variation in relative outputs dwarf those that can be reaped from sharing risks at the business cycle frequency 25

To the extent that rational agents will buy exactly that amount of insurance that equates marginal costs and benefits, this suggests that the marginal cost of insuring against permanent risk is much higher than that of insuring against transitory risk. In particular, this finding rules out any explanation of the lack of international consumption risk sharing that is based on transaction costs:

Recall that insurance against permanent shocks requires the use of statecontingent assets, whereas transitory shocks can be smoothed with bonds and loans alone. Fixed transaction costs such as language barriers, institutional and regulatory differences but also the cost of collecting information would

\footnotetext{
${ }^{24}$ This finding is in line with earlier results in Canova and Ravn (1996) who also found that in international data low-frequency risks seem to be insured less than high frequency fluctuations.

${ }^{25}$ See e.g. the calculations in van Wincoop (1999) and compare also the calculations in Lucas (1987).
} 
therefore have to vary widely across asset classes in order to explain our findings. We do not think that this is the case.

It could, however, still be the case that higher variable transaction costs (such as trading costs that are often volume dependent) for state-contingent assets might explain differential degrees of risk sharing for permanent and transitory shocks. However, empirical evidence suggests that there is a lot of trade in international equity markets and that gross capital flows are big in relation to net flows (see e.g. Golub (1990)) and that turnover in international equity portfolios is high. Tesar and Werner (1995) note that low net international investment positions come along with a high volume of cross-border capital flows and a high turnover rate on foreign equity investments relative to turnover on domestic equity markets. Actually, the turnover rate on international equity investments is high both when compared to the turnover rate in the investor's country of origin, and when compared to the market of origination of the foreign security. Against the backdrop of this evidence, variable transactions costs are an unlikely explanation for the differential degrees of risk sharing for permanent and transitory shocks.

Our findings rather point us towards particular forms of market incompleteness (which could of course be interpreted as prohibitive fixed cost of investment) as the more likely explanation of the home bias and the observed differential degrees of risk sharing for permanent and transitory shocks.

Kehoe and Perri (2002) have suggested that international financial markets could be endogenously incomplete because contracts could be less enforceable between countries than between regions. Our results would support this explanation but they also suggest that while markets may be more complete within countries than between them, they are still clearly incomplete even within countries (note that 40 percent of permanent idiosyncratic output variability remains uninsured even in U.S. data).

Our results also tie in with other findings from recent empirical and theoretical research. Kraay, Loayza, Serven and Ventura (2000) find that the international component of most countries' portfolios is heavily biased towards loans and bonds. On the theoretical side, Baxter and Crucini (1995) have shown that the full risk sharing allocations that ensue as equilibria in models with complete markets can be approximated by models that feature only non-state-contingent assets - as long as shocks are not too persistent. Plausibly, the fact that insurance against permanent shocks is incomplete while transitory shocks get smoothed almost completely ex post could be explained by the findings in these papers. 


\section{$5.1 \quad$ Summary}

Our aim in this paper was to draw a map of an area of our ignorance, i.e. how countries share risks at various time horizons. In so doing, we have expanded the set of stylized facts provided in ASY (1996) and SY (1998) along several important dimensions. As we have shown, considering the structure of dynamic risk sharing at different horizons can provide important insights into the possible sources of the home bias. While this paper has not set out to test one particular explanation of the lack of international consumption risk sharing, our results establish some stylized facts that can serve as a benchmark for theoretical models:

1. U.S. federal states share roughly one half of their idiosyncratic risk ex ante, whereas there is almost no ex ante insurance at the international level. In both data sets, the contribution of the ex ante channel is virtually independent of the forecasting horizon. Conversely, the amount of ex post risk sharing achieved is about the same in both data sets but declines from about 30 to 50 percent in the short run to generally less than ten percent in the long run. Taken together, these findings imply that the lack of international consumption risk sharing worsens in the long run.

2. The lack of international consumption insurance is in fact a failure to insure against permanent fluctuations whereas transitory shocks, i.e. risks at the business cycle frequency, get almost completely shared. This finding allows us to rule out transaction costs based explanations of the home bias and points us towards endogenous market incompleteness that makes insuring against permanent shocks almost prohibitively expensive at the international level.

3. An additional and unrelated contribution of this paper was to provide evidence based on principal components analysis that shows that shocks to output are the predominant source of variability in standard data sets. This documents the empirical validity of risk sharing regressions in the spirit of ASY both in static and dynamic settings. 


\section{References}

Anderson, Theodore W. and Cheng Hsiao, "Formulation and Estimation of Dynamic Models Using Panel Data," Journal of Econometrics, January 1982, 18 (1), 47-82.

Arellano, Manuel, "A Note on the Anderson-Hsiao Estimator for Panel Data," Economics Letters, December 1989, 31 (4), 337-341.

Asdrubali, Pierfederico, Bent E. Sørensen, and Oved Yosha, "Channels of interstate risk sharing: United States 1963-90," Quarterly Journal of Economics, 1996, 111, 1081-1110.

Athanasoulis, Stefano G. and Eric van Wincoop, "Growth Uncertainty and Risk Sharing," Journal of Monetary Economics, June 2000, 45 (3), $447-505$.

__ and _ _ "Risksharing within the US: What Do Financial Markets and Fiscal Federalism Accomplish?," Review of Economics and Statistics, November 2001, 83 (4), 688-698.

and Robert J. Shiller, "World Income Components: Measuring and Exploiting Risk Sharing Opportunities," American Economic Review, September 2001, 91 (4), 1031-1054.

Backus, David K., Patrick J. Kehoe, and Finn E. Kydland, "International Real Business Cycles," Journal of Political Economy, 1992, 100 (4), $745-775$.

Baltagi, Badi H., Econometric Analysis of Panel Data, 2 ed., John Wiley and Sons, 2001.

Baxter, Marianne and Mario J. Crucini, "Business Cycles and the Asset Structure of Foreign Trade," International Economic Review, 1995, 36 (4), 821-853.

Beveridge, Stephen and Charles R. Nelson, "A New Approach to Decomposition of Economic Time Series into Permanent and Transitory Components with Particular Attention to Measurement of the Business Cycle," Journal of Monetary Economics, 1981, 7 (2), 151-174.

Canova, Fabio and Morten Ravn, "International consumption risk sharing," International Economic Review, 1996, 37 (3), 573-601. 
Coe, Patrick J. and James M. Nason, "Long-run Monetary Neutrality and Long Horizon Regressions," Journal of Applied Econometrics, May/June 2004, 19 (3), 355-373.

Feldstein, Martin S. and Charles Yuji Horioka, "Domestic Saving and International Capital Flows," Economic Journal, June 1980, 90 (358), $314-329$.

French, Kenneth R. and James M. Poterba, "Investor diversification and international equity markets," American Economic Review, 1991, $81(2), 222-26$.

Golub, Stephen S., "International capital mobility: Net versus gross stocks and flows," Journal of International Money and Finance, 1990, 9 (4), 424-39.

Hodrick, Robert J., "Dividend Yields and Expected Stock Returns: Alternative Procedures for Inference and Measurement," Review of Financial Studies, 1992, 5 (3), 357-386.

Hoffmann, Mathias, "International Macroeconomic Fluctuations and the Current Account," Canadian Journal of Economics, May 2003, 36 (2), 401-420.

Holtz-Eakin, Douglas, Whitney Newey, and Harvey S. Rosen, "Estimating vector autoregressions with panel data," Econometrica, November 1988, 56 (6), 1371-1395.

Im, Kyung So, M. Hashem Pesaran, and Yongcheol Shin, "Testing for Unit Roots in Heterogeneous Panels," Journal of Econometrics, July 2003, 115, 53-74.

Johansen, Søren, Likelihood Based Inference in Cointegrated Vector Autoregressive Models, Oxford University Press, Oxford, 1995.

Kehoe, Patrick J. and Fabrizio Perri, "International Business Cycles with Endogenous Incomplete Markets," Econometrica, 2002, 70 (3), 907-28.

King, Robert, Charles I. Plosser, James H. Stock, and Mark W. Watson, "Stochastic Trends and Economic Fluctuations," American Economic Review, 1991, 81, 819-40. 
Kocherlakota, Narayana R., "Implications of Efficient Risk Sharing without Commitment," Review of Economic Studies, October 1996, 63 (4), 595-609.

Kraay, Aart, Norman Loayza, Luis Serven, and Jaume Ventura, "Country Portfolios," NBER Working Paper 77995, 2000.

Lane, Philip D. and Gian Maria Milesi-Ferretti, "International Financial Integration," IMF Staff Papers, 2003, 50 (Special Issue), 82-113.

Lucas, Robert J., Models of Business Cycles, Oxford: Basil Blackwell, 1987.

Mark, Nelson C. and Donggyu Sul, "Cointegration vector estimation by panel DOLS and long-run money demand," Oxford Bulletin of Economics $\&$ Statistics, 2004, forthcoming.

Mélitz, Jacques and Frédéric Zumer, "Interregional and International Risk-Sharing and Lessons for EMU," Carnegie-Rochester Conference Series on Public Policy, December 1999, 51, 149-188.

Negro, Mario Del, "Asymmetric shocks among U.S. states," Journal of International Economics, 2002, 56, 273-297.

Pesaran, M. Hashem and Ron Smith, "Estimating long-run relationships from dynamic heterogeneous panels," Journal of Econometrics, 1995, 68, 79-113.

Phillips, Peter C. B. and Hyungsik R. Moon, "Linear Regression Limit Theory for Nonstationary Panel Data," Econometrica, September 1999, $67(5), 1057-1111$.

Sørensen, Bent E. and Oved Yosha, "International risk sharing and European Monetary Unification," Journal of International Economics, 1998, 45, 211-38.

_ and _ _ , "Producer Prices versus Consumer Prices in the Measurement of Risk Sharing," unpublished manuscript, 2002, Tel Aviv University.

Stock, James H. and Mark W. Watson, "Testing for common trends," Journal of the American Statistical Association, 1988, 83 (404), 10971107. 
Tesar, Linda L. and Ingrid M. Werner, "Home Bias and High Turnover," Journal of International Money and Finance, 1995, 14 (4), $467-92$.

Valkanov, Rossen, "Long-horizon regressions: Theoretical results and applications," Journal of Financial Economics, May 2003, 68 (2), 201-232.

van Wincoop, Eric, "How big are potential welfare gains from international risk sharing?," Journal of International Economics, 1999, 47, 109-135.

von Hagen, Jürgen, "Fiscal Policy and Intranational Risk Sharing," in Gregory D. Hess and Eric van Wincoop, eds., Intranational Macroeconomics, Cambridge: Cambridge University Press, 2000. 


\section{Data Appendix}

\section{International Data}

The data are from OECD National Accounts Main Aggregates volume 1, OECD Economic Outlook, period 1960-1996. The OECD countries in our sample consist of all 1996 members except Mexico and Turkey. A special case is Germany due to German unification: The data contain a consistent series for 'West Germany' from 1960 through 1994, and a series for the unified Germany from 1990 through 1996.

We also consider several subsets of countries: 'OECD' refers to all 1996 members of the OECD except Mexico and Turkey, while 'OECD core' denotes the G7 plus Australia, Austria, Belgium, Denmark, Finland, and Sweden. 'EU15' refers to all $15 \mathrm{EU}$ members as of 1996. 'EMU 11' comprises the eleven starting members of EMU.

Gross domestic product (GDP), gross national product (GNP) and household final consumption expenditure $(\mathrm{C})$ are all deflated using the consumer price index (obtained by dividing series for private final consumption expenditure in current prices by the series for private final consumption expenditure in 1990 prices). Population data are mid-year estimates. Exchange Rates data are market rates averaged over each year. Exchange rates for Germany refer to the Deutsche Mark.

\section{Intranational Data}

The U.S. regional data are the data used in ASY and were downloaded from Oved Yosha's webpage. They consist of gross-state product and personal income data from the Bureau of Economic Analysis (BEA) and range from 1963-1990. Personal consumption data at the state level is not available. ASY have therefore used retail sales data. Unfortunately, retail sales are only a part of total personal consumption, so in order to obtain an estimate of total personal consumption. ASY re-scaled the retail sales data by the ratio of aggregate U.S. private consumption to aggregate U.S. retail sales. Finally, state and local government consumption is added to obtain state consumption. 


\section{Technical Appendix}

\section{Permanent-transitory decomposition}

Here, we show why the relative variance contributions of permanent and transitory shocks are independent of how the permanent and transitory shocks are identified among themselves.

Assume that $\boldsymbol{S}_{\pi}$ and $\boldsymbol{S}_{\tau}$ are appropriately dimensioned non-singular matrices such that $\boldsymbol{\pi}_{0}=\boldsymbol{S}_{\pi} \boldsymbol{\pi}$ and $\tau_{0}=\boldsymbol{S}_{\tau} \tau$. Recall that the coefficients of the reduced-form moving average representation of $\boldsymbol{\Delta} \boldsymbol{X}_{t}$ are given by $\mathrm{C}(\mathrm{L})$. Then the impulse response of the system to permanent and transitory shocks is $\mathbf{C}(\mathbf{L}) \mathbf{P}^{-1}$ where

$$
\boldsymbol{P}=\left[\begin{array}{c}
\boldsymbol{S}_{\pi} \boldsymbol{\gamma}_{\perp}^{\prime} \\
\boldsymbol{S}_{\tau} \boldsymbol{\gamma}^{\prime} \boldsymbol{\Omega}^{-1}
\end{array}\right]
$$

is just the matrix mapping the reduced-form disturbances into their permanent and transitory components.

It is easily verified that

$$
\boldsymbol{P}^{-1}=\left[\begin{array}{ll}
\boldsymbol{\Omega} \gamma_{\perp}\left(\boldsymbol{\gamma}_{\perp}^{\prime} \boldsymbol{\Omega} \boldsymbol{\gamma}_{\perp}\right)^{-1} \boldsymbol{S}_{\pi}^{-1} & \gamma\left(\boldsymbol{\gamma}^{\prime} \boldsymbol{\Omega}^{-1} \boldsymbol{\gamma}\right)^{-1} \boldsymbol{S}_{\tau}^{-1}
\end{array}\right]
$$

Then note that the covariance of $\left[\begin{array}{ll}\boldsymbol{\pi}_{0}^{\prime} & \tau_{0}\end{array}\right]^{\prime}$ is given by

$$
\Sigma=\left[\begin{array}{cc}
\boldsymbol{S}_{\pi} \boldsymbol{\gamma}_{\perp}^{\prime} \boldsymbol{\Omega} \boldsymbol{\gamma}_{\perp} \boldsymbol{S}_{\pi}^{\prime} & \mathbf{0} \\
\mathbf{0} & \boldsymbol{S}_{\tau} \boldsymbol{\gamma}^{\prime} \boldsymbol{\Omega}^{-1} \gamma \boldsymbol{S}_{\tau}
\end{array}\right]
$$

Hence, the mean-square prediction error is

$$
\begin{aligned}
\boldsymbol{\Omega}(k) & =\sum_{l=1}^{k}(k-l)^{2} \boldsymbol{C}_{l} \boldsymbol{\Omega} \boldsymbol{C}_{l}^{\prime}=\sum_{l=1}^{k}(k-l)^{2} \boldsymbol{C}_{l} \boldsymbol{P}^{-1} \boldsymbol{\Sigma}\left(\boldsymbol{P}^{-1}\right)^{\prime} \boldsymbol{C}_{l}^{\prime} \\
& =\sum_{l=1}^{k}(k-l)^{2} \boldsymbol{C}_{l}\left[\boldsymbol{\Omega} \boldsymbol{\gamma}_{\perp}\left(\boldsymbol{\gamma}_{\perp}^{\prime} \boldsymbol{\Omega} \boldsymbol{\gamma}_{\perp}\right)^{-1} \boldsymbol{\gamma}_{\perp}^{\prime} \boldsymbol{\Omega}+\boldsymbol{\gamma}\left(\boldsymbol{\gamma}^{\prime} \boldsymbol{\Omega}^{-1} \boldsymbol{\gamma}\right)^{-1} \boldsymbol{\gamma}^{\prime}\right] \boldsymbol{C}_{l}^{\prime}(17) \\
& =\boldsymbol{\Omega}^{P}(k)+\boldsymbol{\Omega}^{T}(k)
\end{aligned}
$$

where

$$
\begin{aligned}
& \boldsymbol{\Omega}^{P}(k)=\sum_{l=1}^{k}(k-l)^{2} \boldsymbol{C}_{l}\left[\boldsymbol{\Omega} \gamma_{\perp}\left(\boldsymbol{\gamma}_{\perp}^{\prime} \boldsymbol{\Omega} \gamma_{\perp}\right)^{-1} \boldsymbol{\gamma}_{\perp}^{\prime} \boldsymbol{\Omega}\right] \boldsymbol{C}_{l}^{\prime} \\
& \boldsymbol{\Omega}^{T}(k)=\sum_{l=1}^{k}(k-l)^{2} \boldsymbol{C}_{l}\left[\boldsymbol{\gamma}\left(\boldsymbol{\gamma}^{\prime} \boldsymbol{\Omega}^{-1} \boldsymbol{\gamma}\right)^{-1} \boldsymbol{\gamma}^{\prime}\right] \boldsymbol{C}_{l}^{\prime}
\end{aligned}
$$


are the mean squared prediction errors associated with the permanent and transitory shocks.

\section{Panel VAR estimation}

In a landmark paper, Holtz-Eakin, Newey and Rosen (1988) - HNR for short - explained how to estimate VARs in a panel framework. Here, we discuss our implementation of their method for the cointegrated VAR. We start by adjusting the error correction representation (12) to the panel framework:

$\boldsymbol{\Delta} \boldsymbol{X}_{j t}=\boldsymbol{\mu}+\sum_{l=1}^{p-1} \boldsymbol{\Gamma}_{l} \boldsymbol{\Delta} \boldsymbol{X}_{j, t-l}+\boldsymbol{\gamma} Z_{j t-1}+\boldsymbol{f}_{j}+\boldsymbol{\lambda}_{t}+\boldsymbol{u}_{j t} \quad j=1, \ldots, K ; t=p+1, \ldots, T$

where $Z_{j t-1}=\boldsymbol{\delta}^{\prime} \boldsymbol{X}_{t-1}$ is the error-correction term and $p$ is the lag order of the level VAR. Now, all variables vary by $j$ and $t$. $\boldsymbol{f}_{j}$ is the vector of countryspecific effects and $\boldsymbol{\lambda}_{t}$ are time-specific effect. As described in the main text, we already capture time-specific effects by subtracting the populationweighted OECD or US-wide average, i.e. all elements of $\boldsymbol{X}_{j t}$ are in relative form. We will therefore neglect time specific effects in our exposition.

However, estimation of (19) brings up a new econometric problem: since $\boldsymbol{\Delta} \boldsymbol{X}_{j t}$ is a function of $\boldsymbol{f}_{j}, \boldsymbol{\Delta} \boldsymbol{X}_{j, t-1}$ is also a function of $\boldsymbol{f}_{j}$. Therefore, $\boldsymbol{\Delta} \boldsymbol{X}_{j, t-1}$, a right-hand regressor in (19), is correlated with the error term. This renders the simple OLS estimator of (19) biased and inconsistent even if the $\boldsymbol{u}_{j t}$ are not serially correlated. For the standard fixed effects (FE) estimator, the 'within' transformation wipes out the country-specific effects $\boldsymbol{f}_{j}$, but $\left(\boldsymbol{\Delta} \boldsymbol{X}_{j, t-1}-\overline{\boldsymbol{\Delta}}_{j, .-1}\right)$ where $\overline{\boldsymbol{\Delta}}_{j,-1}=\sum_{t=2}^{T} \boldsymbol{\Delta} \boldsymbol{X}_{j, t-1} /(T-1)$ will still be correlated with $\left(\boldsymbol{u}_{j, t}-\overline{\boldsymbol{u}}_{j, .}\right)$ even if the $\boldsymbol{u}_{j t}$ are not serially correlated. This is because $\overline{\boldsymbol{u}}_{j \text {, }}$ contains $\boldsymbol{u}_{j, t-1}$ which is correlated with $\boldsymbol{\Delta} \boldsymbol{X}_{j, t-1}$ by construction.

The specification of 19$)$ as a projection implies that the error term $\boldsymbol{u}_{j t}$ satisfies the orthogonality condition

$$
\boldsymbol{E}\left[\boldsymbol{\Delta} \boldsymbol{X}_{j s}^{\prime} \boldsymbol{u}_{j t}\right]=\boldsymbol{E}\left[\boldsymbol{f}_{j}^{\prime} \boldsymbol{u}_{j t}\right] \quad s<t
$$

We can exploit these orthogonality conditions to identify the parameters of the model. Taking first differences on (19), we obtain

$$
\begin{aligned}
\Delta \boldsymbol{X}_{j t}-\boldsymbol{\Delta} \boldsymbol{X}_{j t-1} & =\sum_{l=1}^{p-1} \boldsymbol{\Gamma}_{l}\left(\boldsymbol{\Delta} \boldsymbol{X}_{j, t-l}-\boldsymbol{\Delta} \boldsymbol{X}_{j, t-l-1}\right)+\gamma\left(Z_{j t-1}-Z_{j t-2}\right)+\boldsymbol{v}_{j t} \\
j & =1, \ldots, K ; t=p+2, \ldots, T
\end{aligned}
$$


where

$$
\boldsymbol{v}_{j t}=\boldsymbol{u}_{j t}-\boldsymbol{u}_{j, t-1}
$$

The orthogonality conditions of equation (20) imply that the error term of the transformed equation (21) satisfies the orthogonality condition

$$
\boldsymbol{E}\left[\boldsymbol{\Delta} \boldsymbol{X}_{j s}^{\prime} \boldsymbol{v}_{j t}\right]=\boldsymbol{E}\left[\boldsymbol{f}_{j}^{\prime} \boldsymbol{v}_{j t}\right] \quad s<t-1
$$

Therefore,

$\boldsymbol{W}_{j t}=\left[\left[\begin{array}{c}\Delta \boldsymbol{X}_{j, t-2}-\boldsymbol{\Delta} \boldsymbol{X}_{j, t-3} \\ \Delta Z_{j t-2}\end{array}\right],\left[\begin{array}{c}\boldsymbol{\Delta} \boldsymbol{X}_{j, t-3}-\boldsymbol{\Delta} \boldsymbol{X}_{j, t-4} \\ \Delta Z_{j t-3}\end{array}\right], . .,\left[\begin{array}{c}\boldsymbol{\Delta} \boldsymbol{X}_{j 2}-\boldsymbol{\Delta} \boldsymbol{X}_{j 1} \\ \Delta Z_{j 2}\end{array}\right]\right]$

qualify as instrumental variables. The original parameters are identified if $T \geq p+3 .{ }^{26}$ Note that the number of instruments increases with $t$. Thus, the HNR estimator is more efficient than an IV estimator based on once-lagged endogenous variables alone (as in Anderson and Hsiao, 1982).

Estimation yields the coefficients $\left[\boldsymbol{\Gamma}_{1}, \ldots, \boldsymbol{\Gamma}_{p-1}, \boldsymbol{\gamma}\right]$, and we can calculate the variance-covariance matrix $\Omega^{*}$ of the transformed system. Using (22), we are able to recover the variance-covariance matrix of the original system. The estimated coefficients $\left[\boldsymbol{\Gamma}_{1}, \ldots, \boldsymbol{\Gamma}_{p-1}, \boldsymbol{\gamma}\right]$ can then be used to obtain the coefficient matrices $\boldsymbol{C}_{l}$ of the moving average representation. Finally, we can compute the mean squared prediction error using (9) from which the results in the main text follow immediately.

\footnotetext{
${ }^{26}$ Alternatively, following Arellano (1989) we used "level" values $\boldsymbol{W}_{j t}=$ $\left[\left[\boldsymbol{\Delta} \mathbf{X}_{j, t-2}^{\prime}, Z_{j t-2}\right]^{\prime},\left[\boldsymbol{\Delta} \boldsymbol{X}_{j, t-3}^{\prime}, Z_{j t-3}\right]^{\prime}, . .,\left[\boldsymbol{\Delta} \boldsymbol{X}_{j 2}^{\prime},, Z_{j 2}\right]^{\prime}\right]$ as instruments in which case we also gain one more period for estimation because in this case identification only requires $T \geq p+2$. The results, however are very similar which we consider a robustness check of our empirical strategy.
} 
Table 1: Risk Sharing in the short run and in the long run regression-based evidence

\begin{tabular}{|c|c|c|c|c|c|}
\hline \multicolumn{6}{|c|}{ Country group } \\
\hline & & & $\overline{\mathrm{R}}$ & & $\mathrm{R}$ \\
\hline \multirow[t]{2}{*}{ OECD } & $\beta_{K}$ & 0.01 & $(0.007)$ & -0.02 & $(0.103)$ \\
\hline & $\beta_{C}$ & 0.36 & $(0.010)$ & 0.11 & $(0.143)$ \\
\hline \multirow[t]{2}{*}{ OECD core } & $\beta_{K}$ & -0.01 & $(0.003)$ & -0.03 & $(0.047)$ \\
\hline & $\beta_{C}$ & 0.36 & $(0.014)$ & 0.06 & $(0.178)$ \\
\hline \multirow[t]{2}{*}{ G7 } & $\beta_{K}$ & 0.01 & $(0.002)$ & 0.00 & $(0.045)$ \\
\hline & $\beta_{C}$ & 0.29 & $(0.015)$ & 0.08 & $(0.204)$ \\
\hline \multirow[t]{2}{*}{ EU15 } & $\beta_{K}$ & 0.05 & $(0.014)$ & -0.02 & $(0.171)$ \\
\hline & $\beta_{C}$ & 0.42 & $(0.017)$ & 0.11 & $(0.192)$ \\
\hline \multirow{2}{*}{ EMU11 } & $\beta_{K}$ & 0.06 & $(0.026)$ & 0.04 & $(0.229)$ \\
\hline & $\beta_{C}$ & 0.43 & $(0.028)$ & 0.18 & $(0.233)$ \\
\hline \multirow[t]{2}{*}{ U.S. states } & $\beta_{K}$ & 0.58 & $(0.017)$ & 0.67 & $(0.116)$ \\
\hline & $\beta_{C}$ & 0.28 & $(0.026)$ & -0.16 & $(0.174)$ \\
\hline
\end{tabular}

Source: OECD National Accounts Main Aggregates volume 1, OECD Economic Outlook, period 1960-1996. 'OECD' refers to all 1996 members except Mexico and Turkey. 'OECD core' denotes the G7 plus Australia, Austria, Belgium, Denmark, Finland, and Sweden. 'EU15' refers to all $15 \mathrm{EU}$ members as of 1996. 'EMU 11' comprises the eleven starting members of EMU.

Values in parentheses are standard errors. Those for the long run are corrected for serial correlation in the residuals and for simultaneity. 


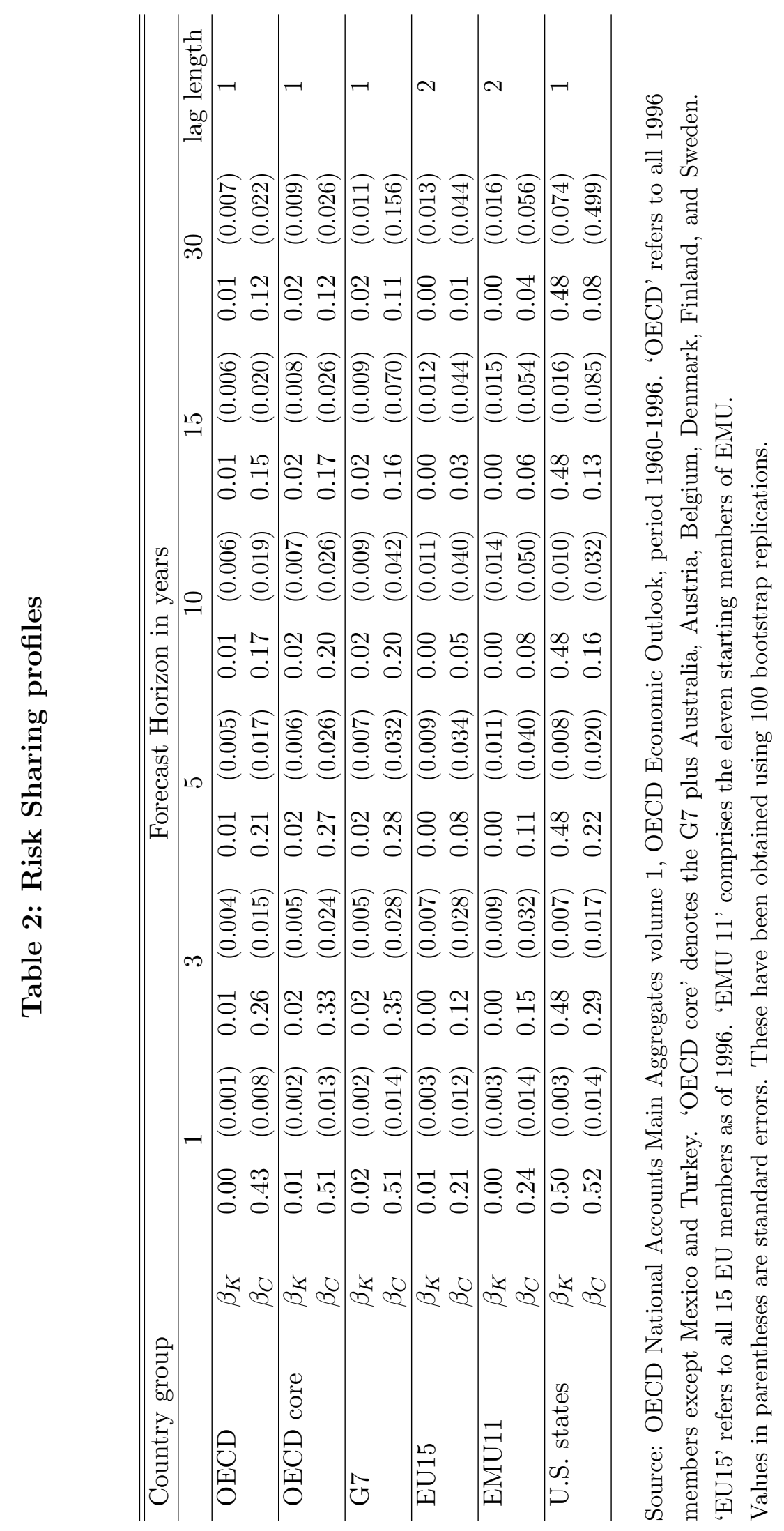


Table 3: Share of first principal component and correlation with GDP shocks

\begin{tabular}{lclll}
\hline \hline & Variance & \multicolumn{3}{c}{ Correl. of 1st PC with } \\
& expl. by 1st PC & $\epsilon_{i 1 t}$ & $\epsilon_{i 2 t}$ & $\epsilon_{i 3 t}$ \\
\hline OECD & $87.48 \%$ & 0.98 & 0.18 & 0.00 \\
OECD core & $90.27 \%$ & 0.98 & 0.27 & 0.04 \\
G7 & $90.71 \%$ & 0.98 & 0.18 & 0.03 \\
EU15 & $70.62 \%$ & 0.97 & 0.21 & 0.01 \\
EMU11 & $72.18 \%$ & 0.97 & 0.26 & 0.01 \\
U.S. states & $66.07 \%$ & 0.74 & 0.66 & 0.12 \\
\hline \hline
\end{tabular}

Source: OECD National Accounts Main Aggregates volume 1, OECD Economic Outlook, period 1960-1996. 'OECD' refers to all 1996 members except Mexico and Turkey. 'OECD core' denotes the G7 plus Australia, Austria, Belgium, Denmark, Finland, and Sweden. 'EU15' refers to all $15 \mathrm{EU}$ members as of 1996. 'EMU 11' comprises the eleven starting members of EMU. 


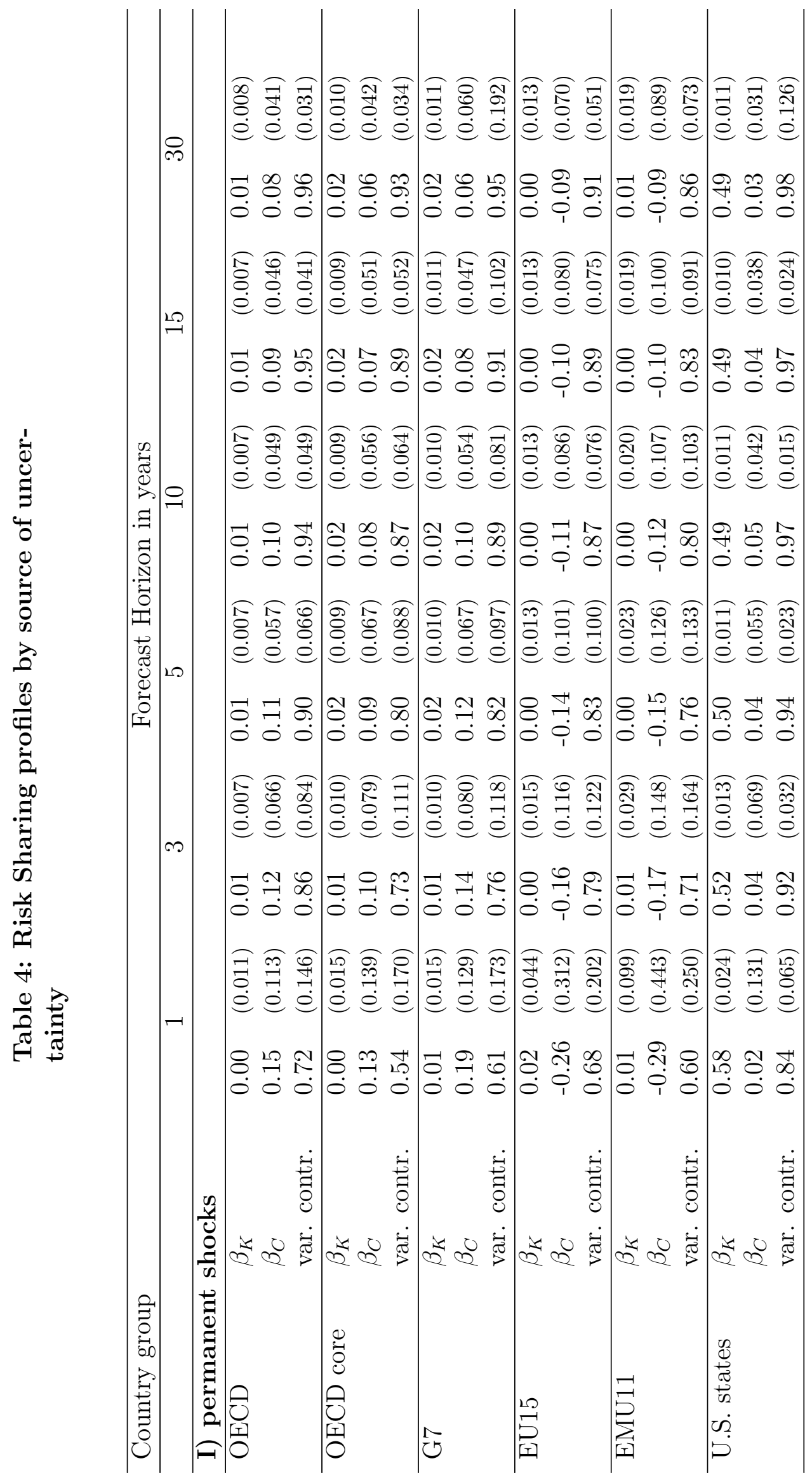




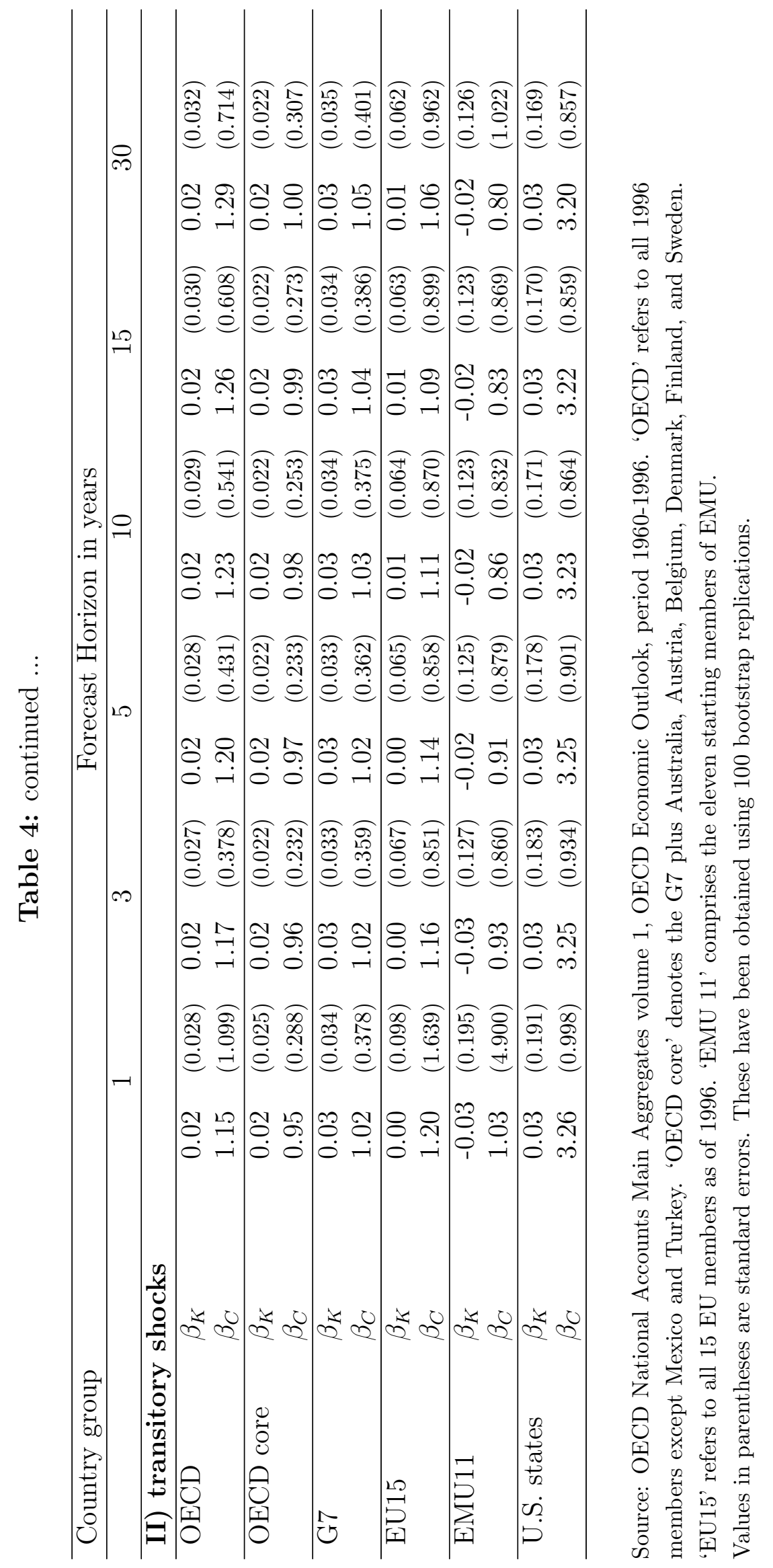

